\title{
Discussion on the Painting in Cave 254 of Mogao Grottoes
}

\author{
Mingjie Bao* \\ Shaanxi Normal University, Xi'an 710062, China \\ *Corresponding author: Mingjie Bao, 1343150811@qq.com
}

\begin{abstract}
Cave 254 of the Mogao Grottoes is one of the most representative grottoes from the Northern Wei Dynasty. The painting of "Laying Down Oneself to Feed the Tiger" on the south wall of the grotto has high artistic value. With changing dynasties and the development of time, the original appearance of the painting has changed. In particular, the color of the whole cave has undergone a subversive change, resulting in many misunderstandings. In this article, the composition, colors, and lines of the painting, "Laying Down Oneself to Feed the Tiger," are discussed in view of the current situation of the cave, and the work is approached from the perspective of painting. The concept of different times of the same painting, its precise and unique layout, as well as development peak of "Laying Down Oneself to Feed the Tiger" are expounded. In this article, the unique artistic level of this mural in the Northern Dynasty is demonstrated along with its importance for present paintings.
\end{abstract}

Keywords: Laying Down Oneself to Feed the Tiger; Composition; Line; Color

Publication date: October 2021; Online publication: October 29, 2021

\section{Composition}

With the introduction of Buddhist art in China, many paintings were seen along the Silk Road and found in many grottoes in the form of frescoes, being expressed in different ways. The paintings are illustrated in Caves 38, 178, and 47 in Karakoram Mountains, Kizil Grottoes, Cave 63 of Kumutula Grottoes, Binyang Middle Cave of Longmen Grottoes, Cave 165 of Qingyang North Grottoes, as well as Cave 127 in Maiji Mountain. However, most of the paintings are rather brief. There are 16 caves (Cave 301, 302, 299, 428, 254, 417, 419, 237, 231, 85, 9, 146, 98, 108, 72, and 55) in the Mogao Grottoes for the size of the painting, "Laying Down Oneself to Feed the Tiger" (Figure 1), from the northern Wei Dynasty to Song Dynasty, of which a unique form of painting has been found in Cave 254, which has become the most unique painting style.

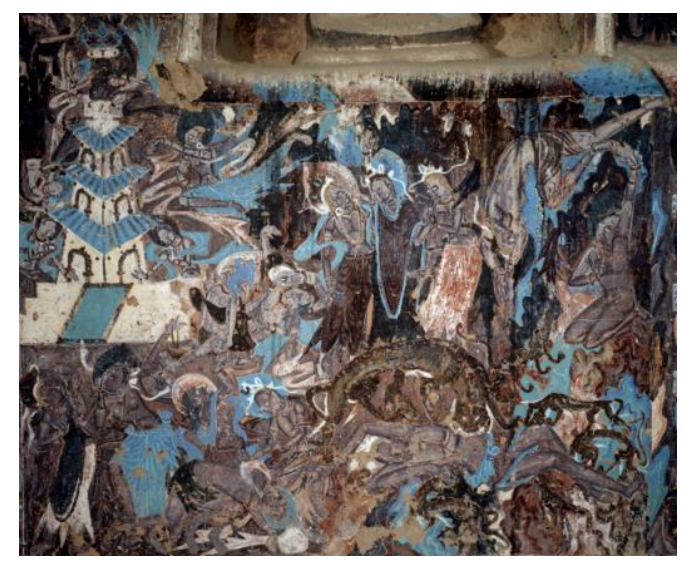

Figure 1. "Laying Down Oneself to Feed the Tiger" in Cave 254 of the Mogao Grottoes 


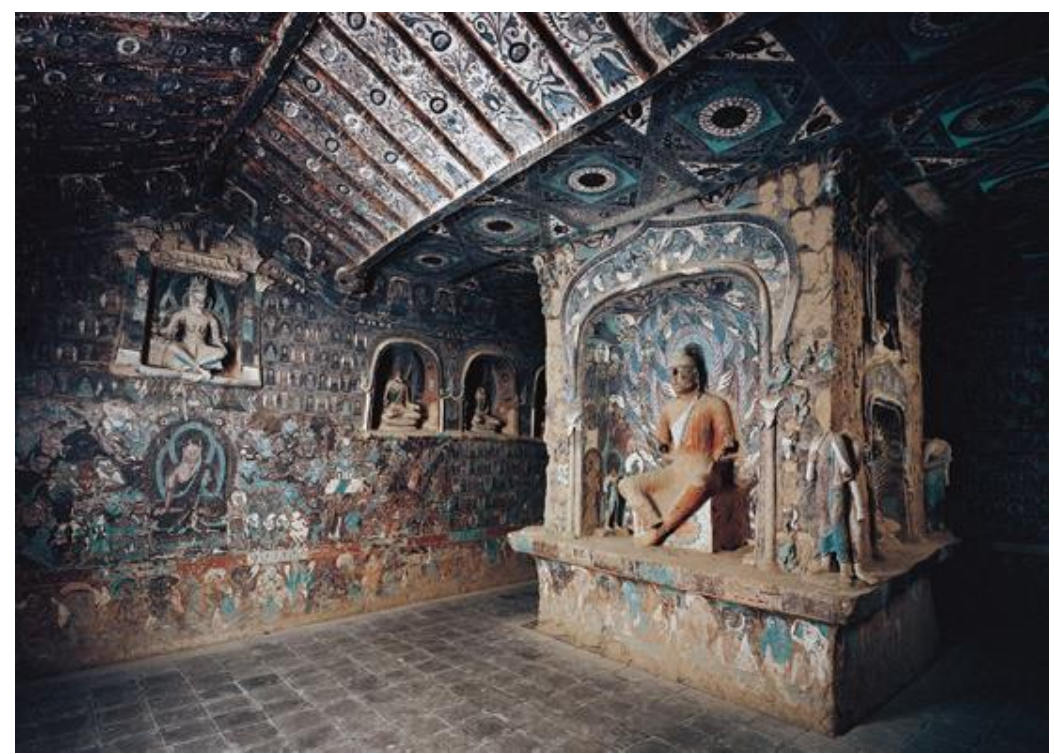

Figure 2. Main room in Cave 254 of the Mogao Grottoes

In Cave 254 of the Mogao Grottoes, "Laying Down Oneself to Feed the Tiger" was painted on the southern wall of the main room (Figure 2). It is different from statue paintings, and it is not limited to strict religious rituals. In that sense, painters can break the rules and use their own imagination when drawing such paintings. The composition and layout of the painting plays a crucial role in the whole picture. The attention to composition has been clearly documented as early as during the Southern and Northern Dynasties. The elaboration of the "Six Laws" by Xie He is a summary of picture compositions. "Laying Down Oneself to Feed the Tiger" in Cave 254 has 20 characters, 8 tigers, five goats, two deers, and a monkey strewn at random overlapping mountains. It also displays a solemn monastery in less than two square meters map on the wall with eight different space-time plots (Figure 3), imaging with a windingtype composition. The eight plots are in chronological order: (1) the tiger watching; (2) the thorns; (3) the vertical cliff; (4) meeting the tiger; (5) picking up the skeletons; (6) the news; (7) the cry; (8) the support. The whole picture is solemn and quiet, giving rise to a solemn yet stirring atmosphere.

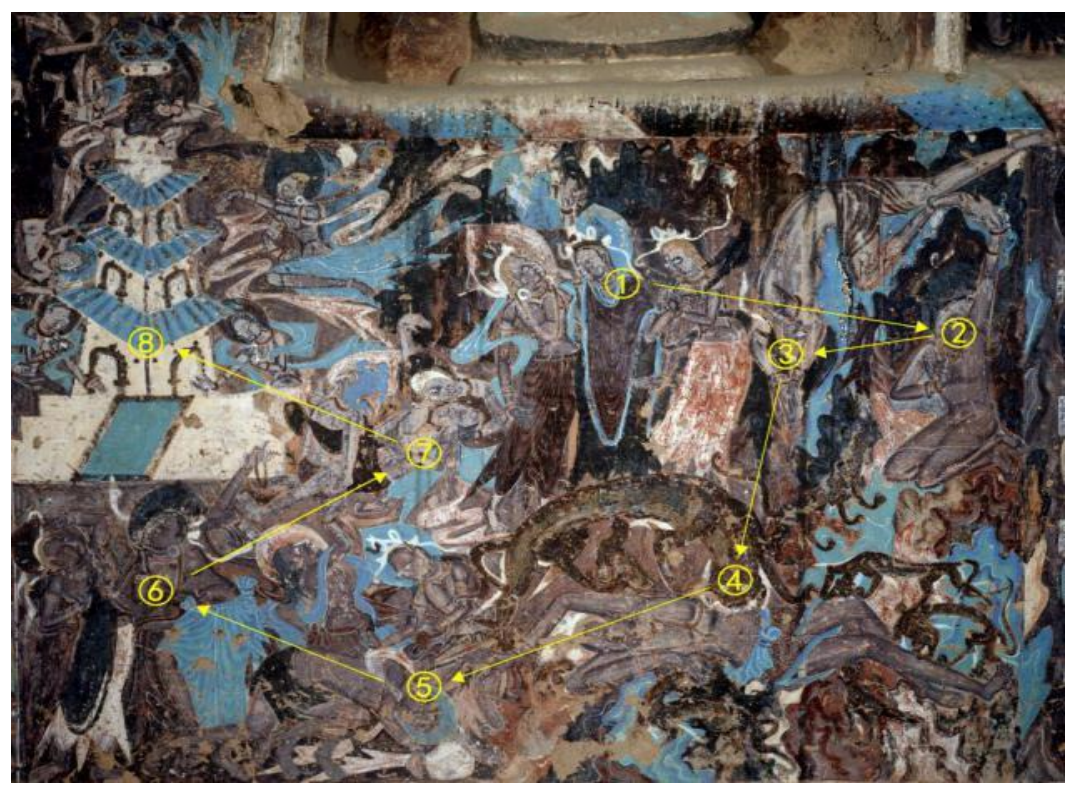

Figure 3. Eight plots of "Laying Down Oneself to Feed the Tiger" in Cave 254 of the Mogao Grottoes 
The painter ingeniously combined a triangle composition with the " $\mathrm{S}$ " curve composition. The triangle composition gives people a sense of stability and durability, while the "S" curve composition exudes a soft and beautiful state. These two compositions are commonly seen in ancient and modern times, but it is rare to see them as complicated and overlapping as that in Cave 254. In the painting, the superimposed relationship of several triangles can be appreciated in each character image along with the shaping of characters by the " $\mathrm{S}$ " curve composition. This kind of composition and modeling leads to a rigid yet soft and stable yet flexible image. The composition adds to the firmness of the moment when Sattva gives up his body for the tiger but did not seize its softness or beauty. The painter expresses the inner world of the characters through the images created by these two ways of composition, thus enabling ancient believers to gain a deeper understanding and perception of the connotations of Buddhist teachings while appreciating the painting.

The 5th scene of the painting shows the image of a sprinkler, which has never been shown in all the paintings of "Laying Down Oneself to Feed the Tiger." The sprinkling of water has the meaning of "awakening" in Buddhism. The cool water awakened the grieving princes from confusion, which made them realize the virtue of Sattva's sacrifice. The white tower in the painting has a special significance; it symbolizes the compassion and virtues of Sattva, which is also the spirit of the whole story. For the audience, it conveys a firm but dignified sorrow without damaging or returning to the exciting atmosphere. By carefully selecting 8 scenes, the painter used the form and color of the characters to fashion the potential of the painting, creating a sense of flow and guiding the viewers' eyes as well as psychological feelings to deeply re-experience the Buddhist story. Looking at the whole picture, it can be appreciated that the painter had formed a downward visual trend with two reference lines under ambush and the vertical direction of the prince's robe, pointing to the suckling tiger. Its posture of holding its head up expresses the joy of reclaiming life, while its foot reflects the sacrificial of Sattva. In the horizontal direction, Sattva, on the right, is connected by a straight line to the white tower on the left, symbolizing the connection of Sattva with Buddhahood. The inner visual frame of the painting is established by two datum lines: one vertical and one horizontal. The movement of potential and rich details engender an orderly and meaningful image. Although it is impossible to fully understand the thoughts of this painter from the Northern Wei Dynasty nor the inner shock that Sattva has caused him, the integration of his beliefs and emotions with originality on that ancient wall can be appreciated, allowing him to pass on his beliefs and emotions to generations after generations through thousands of years. This is the unique charm of an excellent historical and cultural heritage.

\section{Colors}

The painter's originality and the decorations over thousands of years add another kind of profound and historical sense to the caves. The thousands of years of devout belief and construction created there are rich and attractive. With various changes throughout the long history, the painting of "Laying Down Oneself to Feed the Tiger" that is presented today vastly differs from the original appearance during the Northern Wei Dynasty. It can be said that the colors of the painting have changed in each subsequent dynasty and there are many reasons for it. The appearance of the painting seen today has been formed by many factors.

Painters during the ancient times used mineral pigments to create their paintings by grinding and rubbing gemstones directly on the walls. According to the stability of the chemical property of the pigment, the funds provided, as well as the unique geographical and climatic factors in Dunhuang, the different colors on the wall have different degrees of changes over the years. The skin color of the figures is fleshy red, resulting from the mixture with white. There is no doubt that the uniformity of color determines the stability, and by mixing, it increases the instability. Some colors contain lead, which will oxidize and discolor, so the original skin color and red mountains in the painting have been oxidized and turned into greyish black. 
Only blue remains and the historical harmony makes the colors of this mural change from red to blue, from warm to cold, giving a solemn, cool, and lively visual sense. The original warm colors were long gone; thus, viewers often have misunderstanding in view of the cold colors portrayed in the painting.

On the other hand, with the victory of the October Revolution, a remnant of Russian forces fled to Xinjiang Province in China in September 1920. Yang Zengxin, a governor of Xinjiang and army inspector, feared trouble as time went on. After requesting the consent of the Beijing government by telex, he moved the former Lieutenant General Commander of the Tsarist and Russian military region of Qihe Province, Anenkov, and his 469 subordinates to Gansu. In June 1921, Lu Hongtao, the Gansu Provincial Army Inspector, moved the residual army to the Mogao Grottoes of Dunhuang, Gansu Province. Four counties, including Jiuquan, Anxi, Dunhuang, and Yumen, raised funds in support. After Anenkov moved to Mogao Grottoes, he used fire to make rice in the grottoes; thus, many murals were smoked black and many colored sculptures were destroyed. In addition, the Russian soldiers scratched graffiti on the murals, resulting in irreparable losses to the cultural relics in Mogao Grottoes. It is because of the smoke, the dual factors of artificial and natural, along with the reconciliation of time produced countless high-grade grey-colored layers. In view of historical reasons, the color of the cave changed from simple to rich. It changed from countless layers of colors and produced many types of senior grey colors, enriching the murals with a harmonious, solemn yet elegant atmosphere.

The color effect of Dunhuang frescoes is formed by the artists' ingenious combination and collocation of colors, which is closely related to the surrounding environment. As the light inside the cave is dim, with multipurpose grey tones, the images would appear blurry and there would be difficulties in identifying them. Therefore, the color is mainly dyed with pure colors to contrast with each other, enriching the color of the paintings to give away a strong effect. In Dunhuang northern Dynasty frescoes, although there are many colors, there are not many types of colors. The reason why the images present such a rich effect is mainly due to the changes of the same color in terms of depth, color collocation, color contrast, and other aspects, resulting in good artistic expressions and contrasts.

The colors of a painting have a very important role in paintings. Colors can be distinguished from cold and warm, hue, purity, lightness, and other aspects. Colors can affect the visual effect of the whole painting. The colors of a painting can affect people's emotions, especially in religious paintings. Painters usually use color collocation and the processing effect to express the painting in order to provide a stronger appeal for viewers. Hegel wrote in "Aesthetics" that color sensing should be a quality unique to artists, the ability to master tone and to compose on tone, so it is also a basic factor of imagination and creativity of reproduction ${ }^{[1]}$. Kandinsky agreed by saying, "In the sensitive mind, color can play a deeper and more appealing appeal. This gives us a second experience of seeing color, the psychological effect of color ${ }^{[2]}$." Therefore, the color configuration of a painting can bring strong visual impact and psychological effect to the audience. Especially in cases of religious murals, different color combinations and color tendencies would make believers think differently about Buddhist teachings while appreciating the paintings.

Seven colors, including white, brown, black, gray, red, blue, and green, are mainly used in the painting of "Laying Down Oneself to Feed the Tiger." The whole painting presents a cool tone. The combination of blue and green becomes turkish green when used in harmony. In order to improve the brightness of turquoise and red in the picture, white was used before the two colors. In the painting, the white and turquoise are very eye-catching against the background of brown, black, and dark red. The use of white and turquoise makes this solemn and dignified picture quieter. Yan Wenliang stated in a book, "Color Talk" article 32: "Gray and fuzzy colors can set off bright colors; if there is no gray color, bright colors are not that bright ${ }^{[3]}$." It is precisely because of the discoloration and blurring of the dark colors in the painting that the viewers are attracted by the bright white and turquoise as soon as they step into the cave. 


\section{Lines}

The drawing of lines has been one of the important techniques used to express painting since ancient times. Ancient painters have had very rich experience in line drawings. These painters did not only use highly generalized lines to accurately represent the characters in the picture, but also the shapes of different lines to indicate the texture of the object, exerting the function of lines to an extreme. Duan Wenjie once mentioned that line drawing is the main technique in painting; it is subjected to the image as without the image, any line drawing is worthless ${ }^{[4]}$. The use of lines in Dunhuang frescoes is an excellent inheritance of this feature. From Beiliang Dynasty to Yuan Dynasty, line drawing has been used to shape characters for more than 1,000 years. With the change of times and the difference in artistic classification, line drawing has evolved and developed. The murals from the Northern Wei and Northern Zhou Dynasties are often represented by "iron line tracing," especially on the clothes of Buddha statues; fine and strong lines that well display the sense of light yarn penetrating can be appreciated.

The line drawing in Mogao Grottoes during the Northern Dynasty mainly takes the form of ink line, white line, and earth red line; each line plays a different role in the painting. In painting of "Laying Down Oneself to Feed the Tiger" in Cave 254 of the Mogao Grottoes, the earth red line is used as the starting line. In this painting, the earth red line is used to draw the general outline directly on the ground pole, and then the image is repeatedly modified with earth red. After the modification, the blank spaces are painted with earth red as the background. Earth red in mural paintings is easy to be covered by other pigments, so the use of earth red in drafts allows painters to modify and adjust accordingly, which would be convenient in the later stage of the painting.

After the completion of the whole painting, the ink line is used as the setting line to draw the specific image of the characters. "As mural paintings in the grottoes would be worshiped by people for a long time, they are usually neater and more exquisite than mural paintings found in tombs. The extra outlining after the painting highlights the shape of the figures and the charm of the painting, thus attracting and influencing the viewers [4]." The success or failure of the setting line determines the effect of the whole painting. Painters need to use appropriate ink to emphasize the main form along with vivid and accurate outlines to achieve the effect of a clever and vivid portrayal of the characters through their facial features. Due to historical reasons, some of the fixed lines in this painting have long disappeared, but it is still possible to appreciate the use of the fixed lines after careful discovery. For example, in the plot where Sattva's parents were sad upon seeing their son's corpse, the painter had accurately expressed the facial expressions and inner world of the characters by using fixed lines. The ancient painter used a few ink lines to incisively and vividly show the mother's pain of losing her son, thus touching people's hearts.

In this painting, in addition to earth red lines and ink lines, white lines were also used. This eye-catching color line mainly plays a refreshing and decorative role in the painting. White lines are mainly used to draw colored dresses, ribbons, and mountains. It enhances the layers of the image and makes the painted image more eye-catching. White lines are the last step in the whole painting, and they play a very important role similar to ink lines. The white lines in the painting were drawn with "iron line tracing," which is very rigorous, strong, and full of charm. However, because the white lines were not drawn directly on the ground stick and coupled with the coarse white pigment particles, differing from the ink lines, the lines drawn appear to be dry, showing the weight of dry and wet effects. Drawing a white line is no less difficult than drawing a fixed line, and it requires painters to have great skills.

In the painting of "Laying Down Oneself to Feed the Tiger," beautiful lines were used, which combined hardness and softness. In addition to earth red lines, ink lines, and white lines, the colors are also in the form of lines, especially the dress texture and ribbon of the characters in the painting. Although they are all colored with pigments, they show the form of lines. The texture of the ribbon and skirt in the painting comes together with colors as lines, making the picture vivid and full meaning. 
Zhang Yanyuan mentioned in "Famous Paintings of the Past Dynasties" that the the most important thing for figure paintings is for the appearance to show the figure's personality and character, which requires fine skills of painting with lines; in this way, one that paints well is always good at writing as well ${ }^{[5]}$. This painting uses this kind of writing style to express itself. Varying turquoise lines are used in the whole painting to depict the streamers on the characters; the bold and unrestrained strokes provide a more dynamic sense to the streamers. The lines in the painting constantly change in order to give more sense of rhythm. In the painting, the three natural staggered lines did not completely coincide, thus, adding a special sense of hierarchy. The combination of the changes of the lines and their staggered use brings about rich expression. The interlacing and echoing of lines enrich the structure of the painting and depict the inner emotions of the whole image.

\section{Artistic value}

Among the paintings of "Laying Down Oneself to Feed the Tiger" in Dunhuang Mogao Grottoes, Cave 254 was the earliest in existence, in which the painting is different from those in northwest India and Qiuci region of Xinjiang in the early period. In the early stage, the drawing of "Laying Down Oneself to Feed the Tiger" usually only selects a single scene to be portrayed, which generally shows the scene of throwing the tiger from the cliff. Perhaps, such drawing is restricted by the diamond grid pattern, so the painting area is very limited. Although the composition and content of its early painting are relatively simple, they all mainly display the image of Sattva sacrificing his own body, which has become the motif of this story and has been continuously adopted by painters in the drawing of "Laying Down Oneself to Feed the Tiger" over hundreds of years after that.

Although the painting in Cave 254 adopted the motif by repeatedly showing how Sattva sacrificed his own body, it is completely different from other paintings. It combines the single image in the early stage with the clearly recognizable story in Cave 428 to form a complex image with a larger picture. Although this painting has brought some difficulties to the audience in terms of viewing and identification, it has been greatly developed from the previous single image, forming a combined image that is not as simple as the early picture. It shows unique independence and integrity. In addition, it plays an important role as a link between "Laying Down Oneself to Feed the Tiger" in the early period and that in Cave 428. In "The Study of Chinese Decorative Paintings in Past Dynasties," Pang Xunqin stated, "The artistic conception of this painting breaks through the old habits. It keeps the whole story organized in one picture. This opens up a new way for the composition of decorative paintings. Modern frescoes, such as those in Mexico, have developed expressions from this type of composition ${ }^{[6]}$."

Therefore, artists who truly love art are creating spiritual wealth for mankind while satisfying their creative desire. Nothing is more important or essential to a work of art than beauty. Excellent works can only be created with the heart. From the perspective of the development and evolution of the painting of "Laying Down Oneself to Feed the Tiger," it mainly existed with religious symbolism for a long period of time. In other words, the painter's desire and demand for the creation of this story have used the religious spirit as the carrier, such as the white tower, the sky, the dynamic expression of the characters, the arrangement of animals, and the hand that depicts the compassion and dedication of Sattva. All these concentrate on reflecting the spiritual depth of the story. This painting does not only depict the world but also promote Buddhism. The artist adopted the bold innovation of different time but with the same picture, similar to the technique of montage, in order to integrate the characters in different time and scenes into one image, which does not only reflect the plot of the story, but also set off the spiritual depth behind the story. 


\section{Conclusion}

Cave 254 of the Mogao Grottoes has preserved the original paintings of the Northern Wei Dynasty. Although the artists who painted the murals have long disappeared in history, their works travel through time and space to speak deeply to all walks of life. This mural is of great academic value both in terms of art and religion. Even after thousands of years of man-made and natural destruction, the walls of the caves still shine brightly. This work has a mysterious symbolic meaning and because of that, the audience have "different people different wisdom" interpretation, thus inspiring the diversity of art painting.

\section{Disclosure statement}

The author declares that there is no conflict of interest.

\section{References}

[1] Hegel, 1979, Aesthetics [Zhu G, Trans.], Commercial Press, Beijing, 281.

[2] Kandinsky W, 1911, On Spirit in Art [Yu M, Trans.], Chongqing University Press, Chongqing, 70.

[3] Yan W, 1978, Color, Shanghai People's Fine Arts Publishing House, Shanghai, 7.

[4] Duan W, 2007, Art Studies in Mogao Caves, People's Publishing House, Lanzhou, 297.

[5] Zhang Y, 2004, Fan Hsiang Yong Point School. Scroll One of the Famous Paintings of the Past Six, People's Fine Arts Publishing House, Beijing, 13-14.

[6] Pang X, 1982, Research on Chinese Ancient Decorative Painting, Shanghai People's Fine Arts Publishing House, Shanghai, 38. 